\title{
器 \\ Recuperação e conservação de espermatozoides epididimários: Perspectivas e aplicações na espécie felina doméstica
}

\author{
[Recovery and conservation of epididymal sperm: \\ Prospects and applications in the domestic feline species]
}

\section{"Revisão/Review"}

\author{
Brenna Sousa Barbosa ${ }^{1 *}$, Roberta Gonçalves $\mathbf{I z z o}^{2}$, Erika Almeida Praxedes ${ }^{2}$, \\ Denilsa Pires Fernandes ${ }^{1}$, Fernanda Araujo Santos ${ }^{2}$
}

\begin{abstract}
${ }^{1}$ Departamento de Medicina Veterinária, Universidade Estadual do Ceará (UECE), Fortaleza- CE, Brasil. ${ }^{2}$ Centro de Ciências Biológicas e da Saúde, Universidade Federal Rural do Semi-Árido (UFERSA), Mossoró-RN, Brasil. *Autor para correspondência/Corresponding author: E-mail: brennasayuri_bs@ @otmail.com
\end{abstract}

\begin{abstract}
Resumo
A recuperação e criopreservação dos espermatozoides epidídimários é uma ferramenta promissora no resgate e/ou prevenção da perda de material genético de machos valiosos ou estimados, ou mesmo, de animais em risco de extinção. A conservação destes espermatozoides na espécie felina doméstica ainda apresenta resultados conflitantes, dificultando a aplicação da biotécnica na área comercial, para animais de padrão racial desejado. Contudo, inúmeras pesquisas investigam as peculiaridades fisiológicas dos espermatozoides felinos, com o intuído de desenvolver protocolos e meios de criopreservação promissores. Assim, alguns trabalhos já reportaram sucesso na congelação dos espermatozoides epididimários de gatos, bem como, no emprego destas células em técnicas de reprodução assistida (inseminação artificial e fecundação in vitro). Portanto, o presente artigo tem como finalidade explanar os principais avanços na área da recuperação e conservação dos espermatozoides epididimários para os gatos domésticos e, enfatizar as perspectivas futuras destes trabalhos na conservação do germoplasma felino.
\end{abstract}

Palavras-chave: espermatozoide felino; epidídimo; recuperação de espermatozoides; criopreservação.

\begin{abstract}
The recovery and cryopreservation of epididymal sperm is a promising tool in the rescue and prevention of loss of genetic material from valuable and/or estimated males, or even animals at risk of extinction. The conservation of these gametes in the domestic feline species still presents conflicting results, hindering the application of this biotechnology in the commercial area for animals of the desired racial pattern. However, numerous studies investigate the physiological peculiarities of feline sperm with the objective of developing promising cryopreservation protocols and means. Thus, some studies have reported success in the freezing of epididymal sperm, as well as in the use of these cells in assisted reproduction techniques (artificial insemination and in vitro fertilization). Therefore, this article aims to explain the main advances in the area of recovery and conservation of epididymal sperm for domestic cats and to emphasize the future prospects of this work in the conservation of feline germplasm.
\end{abstract}

Keywords: feline sperm; epididymis; sperm recovery; cryopreservation.

\section{Introdução}

A recuperação e criopreservação dos espermatozoides epididimários são biotécnicas potenciais no resgate do material genético de machos valiosos e/ou estimados, visto que permite a obtenção de células viáveis de animais post-

mortem, bem como, o armazenamento destes gametas por tempo indeterminado e sua posterior utilização em programas de reprodução assistida (Chatdarong, 2017). Ademais, a manipulação dos espermatozoides epididimários é uma alternativa 
para resguardar o material genético quando o animal é acometido de alguma patologia que interrompa precocemente seu papel reprodutivo (Oliveira et al., 2010).

Nos felinos, a criopreservação dos espermatozoides ainda é um desafio devido à peculiaridade da teratozoospermia, condição na qual $60 \%$ ou mais dos espermatozoides mostramse morfologicamente anormais, sendo que no gato doméstico esta pode ser expressa esporadicamente, mesmo em animais normais (cerca de 30\%), em decorrência dos fatores ambientais (Pukazhenthi et al., 2006; Emerenciano et al., 2013). Neste sentido, sabe-se que amostras espermáticas de machos teratozoospérmicos apresentam maior susceptibilidade às crioinjúrias, o que dificulta a obtenção de resultados consistentes e confiáveis (Pukazhenthi et al., 1999). Somado a isto, a manipulação dos espermatozoides epididimários requer $\mathrm{o}$ desenvolvimento de protocolos específicos, visto que estas células não se encontram em contato com o plasma seminal e consequentemente, podem ser mais termossensíveis do que as oriundas do sêmen (Hermansson e Axnér, 2007).

As atuais pesquisas na área de reprodução de felinos vislumbram compreender as peculiaridades fisiológicas do gameta masculino, especialmente, a influência da morfologia na qualidade espermática pós-descongelação e habilidade de fertilização, com intuito de viabilizar a aplicabilidade comercial da criopreservação na espécie (Brusentsev et al., 2018; Prochowska et al., 2018). Assim, foi objetivado nesta revisão explanar sobre os avanços da recuperação e criopreservação dos espermatozoides epididimários de gatos domésticos, com ênfase para as perspectivas futuras destes trabalhos na conservação do germoplasma felino.

\section{Características dos espermatozoides epididimários na espécie felina doméstica}

O conhecimento das características do fluido epididimário e dos espermatozoides felinos é crucial para o desenvolvimento de protocolos de criopreservação adequados. Até o presente momento, não se tem dados referentes à caracterização bioquímica do fluído epididimário; contudo, Axénr (2006) reportou, em estudos preliminares, a presença da hipotaurina, taurina e fosfatase alcalina na secreção epididimária do gato doméstico. Alguns trabalhos atuais vêm elucidando necessidades/particularidades dos espermatozoides epididimários.

Recentemente, foi demostrado que espermatozoides recuperados de distintas regiões do epidídimo apresentam diferentes tolerâncias ao estresse osmótico, de modo que os da cauda são mais sensíveis a condições hipertônicas (igual ou superior a $900 \mathrm{mOsm}$ ), quando comparados com os do corpo e da cabeça. Possivelmente, istoé devido à composição diferenciada do fluido epididimário de cada região, associado ao grau de maturidade dos gametas e modificações na sua membrana plasmática durante o trânsito epididimário (Kunkitti et al., 2017). Todavia, espermatozoides da cauda e do corpo do epidídimo apresentam igual habilidade de sofrer capacitação, reação acrossômica e fertilização in vitro (Kunkitti et al., 2015; Kunkitti et al., 2016).

Uma condição peculiar amplamente investigada nos felinos é a teratozoospermia, visto que esta influencia negativamente o sucesso da criopreservação espermática. Células teratozoospérmicas são mais suscetíveis a danos na membrana plasmática, induzidos pela refrigeração, bem como à reação acrossômica prematura e/ou à criocapacitação espermática (Pukazhenthi et al., 1999). Alguns autores acreditam que tal suscetibilidade deve-se a diferenças na composição lipídica das membranas das células teratozoospérmicas em relação às normoespérmicas, contudo, no gato isto não foi elucidado (Hashemitabar et al., 2015; Toniolli et al., 2017).

A teratozoospermia também infere sobre a tolerância osmótica, comprometendo a motilidade e a integridade da membrana dos espermatozoides criopreservados. Sabe-se que células morfologicamente anormais produzem maiores quantidades de espécies reativas de oxigênio, tais como superóxido $\left(\mathrm{O}_{2}^{-}\right)$, peróxido de hidrogênio $\left(\mathrm{H}_{2} \mathrm{O}_{2}\right)$ e hidroxila $\left(\mathrm{OH}^{-}\right)$, o que eleva a susceptibilidade a danos, inclusive no DNA (Pukazhenthi et al., 2001; Souza e Morais, 2016). Neste sentido, Mota e Ramalho-Santos (2006) correlacionaram positivamente anomalias na cabeça do espermatozoide de gatos domésticos com defeitos do DNA detectados por teste de TUNEL.

Terrel et al. (2010) relataram menor motilidade $(60 \%)$ e integridade do acrossoma $(75 \%)$ dos espermatozoides de animais considerados teratozoospérmicos quando comparado com normoespérmicos $(75 \%$ e $85 \%$, 
respectivamente). Somado a tais observações, foi constatado o comprometimento metabólico nas amostras espermáticas teratozoospermicas, no qual a menor produção de lactato e absorção de piruvato e glicose inferiu negativamente na qualidade espermática (Terrel et al., 2010).

Embora a morfologia espermática seja bastante investigada, não se tem nenhum estudo morfométrico com dados detalhados sobre dimensões da cabeça, peça intermediária e cauda do espermatozoide no gato ou nos demais felinos. Logo, pesquisas desta natureza se fazem importantes para geração de valores de referência para células morfologicamente normais na espécie (Martins e Justino, 2015).

\section{Transporte e conservação dos epidídimos}

$\mathrm{O}$ transporte e armazenamento adequado dos complexos testículos-epidídimos (CTE's) é o primeiro passo para obtenção de gametas viáveis e sua posterior conservação. De modo geral, as gônadas podem ser mantidas a temperatura ambiente, por até $5 \mathrm{~h}$, ou resfriadas $\left(4-5^{\circ} \mathrm{C}\right)$, em solução salina ou tampão fosfato-salino (PBS) (Mota-Filho, 2012; Silva, 2012). A utilização de amostras provenientes do epidídimo, após refrigeração, foi realizada inicialmente por Gañán et al. (2009), sendo observado que estes poderiam ser mantidos por até $72 \mathrm{~h}$ a $5^{\circ} \mathrm{C}$, sem perdas significativas de motilidade. Em estudo recente, Angrimani et al. (2018) recomendaram o armazenamento dos CET's por até $48 \mathrm{~h}$, reportando que, após este intervalo, ocorre significativa redução da motilidade, integridade de membrana plasmática e atividade mitocondrial.

Com relação ao meio de conservação, foi proposta a conservação a $4^{\circ} \mathrm{C}$, dos complexos CTE's, em meio TRIS-gema, o qual permitia redução dos danos à estrutura histológica do epidídimo, culminando na manutenção da qualidade espermática pós-recuperação (Tittarelli et al., 2012).

\section{Recuperação espermática}

A recuperação dos espermatozoides a partir do epidídimo pode ser dada através de várias abordagens. No entanto, devido ao pequeno tamanho do epidídimo do gato, as técnicas de fatiamento e de flutuação permitem a obtenção de maior volume de lavado epididimário, bem como, amostras mais concentradas (Lima et al., 2014). Na técnica de flutuação, as estruturas epididimárias são seccionadas, em contato com o meio de recuperação, e os fragmentos mantidos em repouso entre 10-15 minutos, para favorecer a migração dos espermatozoides para o meio (Thuwanut et al., 2015). Por outro lado, no fatiamento, a cauda do epidídimo é fragmentada e comprimida simultaneamente, promovendo o extravasamento do fluido epididimário para o exterior (Angrimani et al., 2015). Outra abordagem utilizada na espécie felina é a técnica de compressão da cauda do epidídimo e ducto deferente, com auxílio de pinças hemostáticas (Savi et al., 2015).

Para realizar a recuperação espermática é necessário empregar diluidores compatíveis às características dos espermatozoides da espécie (Lima et al., 2014). De modo geral, preconiza-se soluções de lavagem a base de tampão Trishidroximetil-aminometano (TRIS) ou ácido sulfônico N-tris-hidroximetil-metil-2aminometano (TES), adicionados de algum substrato energético como a glicose, frutose ou lactose, não havendo diferença entre esses na conservação dos espermatozoides felinos (Jiménez et al., 2013, Burannamnuay, 2017).

A associação do TES-TRIS também apresenta bons resultados de motilidade espermática, com média de 71,1\% (Waurich et al., 2010; Vick et al., 2012; Lombo et al., 2012). Outros diluidores empregados são o Tampão fosfato-salino (PBS) (Vizuete et al., 2014), Meio 119 Hepes modificado (M119) (Klaus et al., 2016) e Meio Dulbecco MEM F-10 (Ham's-10) (Stachecki et al., 1994), sendo o último amplamente utilizado na conservação dos espermatozoides de felinos selvagens (Baudi et al., 2008). O meio Tyrode's modificado (spermTALP) foi igualmente apontado como excelente diluidor, permitindo motilidade espermática (42,5 $\pm 4,5 \%)$ e viabilidade $(68,1 \pm 3,7 \%)$ superiores após recuperação e incubação por $2 \mathrm{~h}$ a $37{ }^{\circ} \mathrm{C}$ quando comparado com o TRIS $(1,0 \pm 0,7 \%$ e 67,7 $\pm 2,4 \%$ para motilidade e viabilidade, respectivamente); possivelmente, os resultados superiores observados para o meio TALP estão relacionados a presença de íons de cálcio $\left(\mathrm{Ca}^{2+}\right)$, bicarbonato $\left(\mathrm{HCO}_{3}-\right)$ e albumina sérica bovina (BSA), que induzem modificações na célula espermática e/ou inibem a atividade da fosfadiesterase, aumentando os níveis de AMPc e consequentemente, a motilidade espermática (Buranaamnuay, 2013).

Meios naturais têm sido testados para espermatozoides felinos. Neste contexto, a água de coco em pó $\left(\mathrm{ACP}^{\circledR}\right)$ mostrou-se como uma 
alternativa promissora, permitindo uma média de motilidade total de 50,15\%, pós-recuperação epididimária (Emerciano et al., 2013; Lima et al., 2016). Contudo, é válido destacar que a escolha do diluidor deve estar em consenso com o emprego final dos espermatozoides (inseminação artificial, refrigeração e/ou congelação), em virtude da interação entre os constituintes, como crioprotetores e aditivos (Bertol et al., 2013).

\section{Criopreservação dos espermatozoides epididimários}

O primeiro trabalho com criopreservação de espermatozoides epididimários felinos se deu na década de 90, quando Hay e Goodrowe (1993) investigaram a capacidade de fertilização destes gametas após coleta e refrigeração, reportando a competência dos mesmos em iniciar as primeiras fases da fertilização: ligação com a zona pelúcida (70,4\% e $54,2 \%$ para espermatozoides frescos e resfriados, respectivamente) e penetração ( $5 \%$ para espermatozoides fresco e $28 \%$ para resfriados) após uma hora de incubação com oócitos de hamster.

De modo geral, os primeiros protocolos adaptados para a conservação do germoplasma felino consistiam na congelação das amostras espermáticas sob a forma de pellets. Para isto, gotas de, aproximadamente, $30 \mu \mathrm{l}$ de sêmen eram diluídas e dispostas em gelo seco, com posterior exposição ao nitrogênio líquido e armazenadas em botijões criogênicos (Platz et al., 1978; Spindler e Wildt, 1999). Contudo, devido ao elevado risco de contaminação microbiológica e, com intuito de melhorar os resultados pós-descongelação, que até hoje apresentam resultados variáveis de motilidade e viabilidade, foram desenvolvidos novos métodos de congelação e recipientes para o armazenamento dos gametas criopreservados, que vão desde de palhetas de $0,25 \mathrm{ml}$ ou $0,50 \mathrm{ml}$ (sendo a primeira mais utilizada) à criotubos de poliestireno (Buranaamnuay, 2017).

Atualmente, preconiza-se a refrigeração dos espermatozoides felinos a $4{ }^{\circ} \mathrm{C}$ por 60 min, seguida da exposição a vapores de nitrogênio, por $20 \mathrm{~min}$, e estocagem em nitrogênio líquido $\left(-196{ }^{\circ} \mathrm{C}\right)$ (Cocchia et al., 2010; Macente et al., 2012, Buranaamnuay, 2015) ou ultrafreezers $\left(-75^{\circ} \mathrm{C}\right)$, por até 120 dias (Buranaamnuay, 2018). Outros autores optam por realizar a curva de congelação por 2 h (Hay e Goodrowe, 1993; Waurich et al., 2010; Brusentsev et al., 2018), não sendo observado uma melhora da motilidade pósdescongelação entre estes dois protocolos.

Recentemente foi proposto o arrefecimento inicial dos espermatozoides a $15{ }^{\circ} \mathrm{C}$ ou $10{ }^{\circ} \mathrm{C}$, seguida do resfriamento lento $\left(-0,27{ }^{\circ} \mathrm{C} / \mathrm{min}\right.$ e $0,06{ }^{\circ} \mathrm{C} / \mathrm{min}$, respectivamente) até $4{ }^{\circ} \mathrm{C}$ (temperatura de equilíbrio), no qual permaneceram por 5 min e posterior, submissão a vapores de nitrogênio por 15 min (aproximadamente - 167 ${ }^{\circ} \mathrm{C}$ ), obtendo valores de motilidade progressiva pós-descongelação de 53,9 \pm 9,6\% e 55,3 \pm 9,9\%, respectivamente (Klaus et al., 2016). Assim, para a conservação da qualidade espermática faz-se necessário o emprego de curvas lentas de refrigeração com intuito de minimizar os criodanos às membranas biológicas, em especial, à acrossomal, na qual a taxa de danos pósdescongelação na espécie felina pode atingir 6080\% (Pukazhenthi et al., 1999).

Reforçando o anteriormente dito, em estudos ultraestruturais, Bonaura et al. (2013) comprovaram que curvas rápidas de refrigeração (como a submissão abrupta das células espermáticas a $4^{\circ} \mathrm{C}$ por $20 \mathrm{~min}$, seguida da exposição a vapores de nitrogênio) comprometem significativamente a integridade celular, ocasionando a formação de vacúolos, dobras e/ou rupturas nas membranas plasmáticas $\mathrm{e}$ acrossomais, além de vacuolização nas mitocôndrias. Vizuete et al. (2014), ao proporem a criopreservação ultrarrápida, através da exposição dos espermatozoides epididimários a vapores de nitrogênio, por dois minutos, também observaram queda significativa da motilidade após descongelação (inferior a 20\%).

Além da curva de criopreservação, é crucial que a composição do diluidor de sêmen seja adequada ao metabolismo espermático, para que a funcionalidade dos gametas na seja comprometida e este promova a melhor adaptação da célula durante as etapas da congelação (Toniolli et al., 2015). De modo geral, o diluidor utilizado para criopreservação espermática na espécie felina tem como crioprotetor não penetrante a gema de ovo, em concentrações que variam entre 10 e $20 \%$ e, o glicerol, crioprotetor penetrante, em concentrações de 4 a 5\% (Martins e Justino, 2015; Buranaamnuay, 2017). De igual forma, a temperatura de adição do glicerol e o tempo de glicerolização devem ser padronizados, pois este apresenta toxicidade à célula espermática, podendo ocasionar desnaturação proteica, alterações no glicocálice e nas proteínas da superfície celular, bem como, 
modificações nas interações dos filamentos de actina com consequência negativa sobre a motilidade (Silva e Guerra, 2011). Assim, recomenda-se para o gato, a adição do glicerol a $4^{\circ} \mathrm{C}$, a fim de minimizar os efeitos tóxicos do crioprotetor, em concentrações inferiores a $8 \%$, sendo que o emprego deste a $5 \%$ confere melhor efeito crioprotetor à célula espermática (DecoSouza et al., 2013; VillaVerde et al., 2013).

Associado aos crioprotetores, os aditivos seminais podem ser incorporados aos diluidores, antes ou pós-criopreservação, para auxiliar na sobrevivência das células e da sua capacidade fecundante. Neste contexto, a pasta Equex STM, nas concentrações de 0,5 e $1 \%$, associada ao diluidor TRIS-gema, tem sido amplamente utilizada, devido seu efeito positivo sobre a integridade do acrossoma pós-descongelação, impedindo ou reduzindo mudanças semelhantes a capacitação, através da dispersão das lipoproteínas da gema, tornando-as mais disponíveis no meio e consequentemente, aumentado o seu efeito crioprotetor sob as membranas biológicas (Axnér et al., 2004; Buranaamnuay, 2015; Thuwanut et al., 2015; Kunkitti et al., 2016). Embora adição do Equex seja recomenda durante a congelação, a exposição demasiada das células espermáticas a esta substância pode induzir fluidez excessiva dos componentes lipoproteicos da membrana plasmática, devido sua ação detergente e, acarretar efeito negativo à integridade da mesma (Buranaamnuay, 2015).

Em estudos prévios, foi verificado que a adição de antioxidantes não-enzimáticos, tais como cisteína, vitamina E e L-carnitina, bem como, dos antioxidantes enzimáticos glutationa peroxidase, superóxido desmutase e catalase, aos espermatozoides felinos, conferem melhorias na motilidade e integridade das membranas, pósdescongelação (Thuwanut et al., 2008; Thuwanut et al., 2010; Manee-In et al., 2014). A suplementação do diluidor com enzimas antioxidantes permite a redução da peroxidação lipídica das membranas celulares, através do sequestro/destruição dos radicais livres superproduzidos durante a criopreservação dos espermatozoides, além de, promover a manutenção da integridade do DNA (Thuwanut et al., 2010).

Recentemente, também foi documentado o uso do análogo do ATP (ATPe), pósdescongelação, tanto na espécie felina doméstica (Felis catus) quanto no leopardo-da-indochina (Panthera pardus delacouri) (Thuwanut et al.,
2015; Thuwanut et al, 2017). No gato doméstico, a incubação dos espermatozoides com $2,5 \mathrm{mM}$ de ATPe, por $10 \mathrm{~min}$, mostrou resultados superiores de motilidade dos gametas $(53,3 \pm 4,4 \%$ e $56,7 \pm$ $5,0 \%$ para controle e ATPe, respectivamente) e atividade mitocondrial $(28,7 \pm 4,8 \%$ e $36,4 \pm 5,5 \%$ para controle e ATPe, respectivamente), além de melhorar a taxa de blastocisto in vitro de $28,8 \pm$ $7,4 \%$ (controle) para $36,1 \pm 7,0 \%$ (Thuwanut et al., 2015).

Quanto à descongelação, várias são as temperaturas $\left(37^{\circ} \mathrm{C}, 38^{\circ} \mathrm{C}, 42^{\circ} \mathrm{C}, 65^{\circ} \mathrm{C}, 70^{\circ} \mathrm{C}\right)$ e tempos (6 a 30 segundos) propostos (Axner et al., 2004; Chatdarong et al., 2007; Cocchia et al., 2010; Vick et al., 2012; VillaVerde et al., 2013; Vizuete et al., 2014; Buranaamnuay, 2015; Thuwanut et al., 2015; Klaus et al., 2016; Kunkitti et al., 2016). A escolha do protocolo de descongelação dependerá da curva de congelação estabelecida, sendo assim, espermatozoides submetidos à refrigeração lenta são submetidos a tempo maior de descongelação (Buranaamnuay, 2017).

Outro aspecto técnico que deve ser levado em consideração é a remoção do glicerol pósdescongelação, devido à toxicidade do mesmo à temperatura ambiente. Chatdarong et al. (2010) propuseram a diluição dos espermatozoides descongelados em tampão TRIS, como método de redução dos efeitos tóxicos dos crioprotetores, conseguindo aumentar a motilidade de 59,7 $\pm 9,7 \%$ para $64,2 \pm 10,4 \%$. Em trabalho semelhante, a centrifugação dos gametas, pós-descongelação, em solução colóide de camada única (SLC) foi recomendada como forma de seleção das células com melhor qualidade e para minimizar a contaminação dos espermatozoides epididimários com células epiteliais e hemácias (Chatdarong et al., 2010).

\section{Novas perspectivas}

A criopreservação dos espermatozoides epididimários felinos apresenta protocolos diversificados, todavia, a preservação da motilidade pós-descongelação ainda é uma problemática (Kunkitti et al., 2017). Estudos futuros visando a compreensão da físiologia espermática e as modificações estruturais/funcionais dos espermatozoides durante as etapas da criopreservação são necessários para minimizar as crinjurias (Cheuquemán et al., 2018). $\mathrm{O}$ entendimento dos fenômenos que envolve a teratozoospermia é uma lacuna que também deve ser investigada na espécie, para o melhor 
entendimento das diferenças metabólicas entre os gametas normais e anormais e futuramente, desenvolver protocolos específicos para animais únicos que apresentem elevadas taxas de espermatozoides pleimórficos (Terrel et al., 2010).

A exploração dos aditivos seminais com ação antioxidante ou mesmo, ativadores de motilidade pode ser uma alternativa para aumentar a motilidade e viabilidade dos espermatozoides criopreservados (Manee-In et al., 2014; Thuwanut et al., 2015). O emprego da injeção intracitoplasmática de espermatozoide (ICSI) também pode auxiliar quando as amostras espermáticas apresentam motilidade insatisfatória (Prochowska et al., 2018). Assim, o investimento na ICSI associada com métodos de criopreservação por liofilização é uma opção atraente, visto que é uma técnica altamente promissora para a geração de criobancos com menores custos de manutenção e flexibilidade de armazenamento e transporte (Patrick et al., 2017).

\section{Considerações finais}

A criopreservação dos espermatozoides epididimários de gato doméstico ainda é um desafio. Contudo, pesquisas recentes sobre o metabolismo e crioestresse foram capazes de elucidar algumas características destas células e assim, permitiram a formulação de diluidores mais adequados.

Apenas alguns poucos protocolos relataram a criopreservação bem sucedida com aplicação na fecundação in vitro e na inseminação intrauterina. Porém, estes resultados não são constantes entre os protocolos, ou mesmo replicáveis entre os diferentes laboratórios. Logo, a fisiologia e metabolismo espermático devem ser considerados para o aperfeiçoamento da criopreservação dos espermatozoides epididimários do gato doméstico, vislumbrando a criação de um banco de genes para a espécie que também sirva de modelo para os demais felinos.

Adicionalmente, a compreensão das modificações ocorridas nas células espermáticas durante as etapas da criopreservação é essencial para o desenvolvimento de uma curva de refrigeração/ congelação/ descongelação menos danosas aos gametas felinos.

\section{Referências}

Angrimani, D.S.R.; Lúcio, C.F.; Veiga, G.A.L.; Regazzi, F.M.; Silva, L.C.G.; Nichi, M.; Vannucchi, I.C. Biotécnicas reprodutivas com o emprego de espermatozoides epididimários em cães. Revista Brasileira de Reprodução Animal, 37(4): 323-327, 2015.

Angrimani, D.S.R.; Nagai, K.K.; Rui, B.R.; Bicudo, L.C.; Losano, J.D.A.; Brito,M.M; Francischini, M.C.P.; Nichi, M. Spermatic and oxidative profile of domestic cat (Felis catus) epididymal sperm subjected to different cooling times (24,48 and 72 hours). Reproduction in Domestic Animals, 53(1): 163-170, 2018.

Axnér, E.; Hermansson, U.; Linde-Forsberg, C. The effect of Equex STM paste and sperm morphology on post-thaw survival of cat epididymal spermatozoa. Animal

Reproduction Science, 84(1): 179-191, 2004.

Axnér, E. Sperm maturation in the domestic cat. Theriogenology, 66(1): 14-24, 2006.

Baudi, D.L.K.; Jewgenow, B.S.; Pukazhenthi,K.M.;

Spercoski ${ }^{\text {a }}$,A.S.;Santos,A.L.S.; Reghelin, M.V.; Candido, M.L.; Javorouski, G.; Müller,R.N.M. Influence of cooling rate on the ability of frozen-thawed sperm to bind to heterologous zona pellucida, as assessed by competitive in vitro binding assays in the ocelot (Leopardus pardalis) and tigrina (Leopardus tigrinus). Theriogenology, 69(2): 204-211, 2008.

Bertol, M. A.F; Weiss, R.R.; Fujita, A.S.; Kozicki, L.E.; Abreu, A.C.M.R; Pereira, J.F.S. Dois diluentes comerciais na criopreservação de espermatozoides do epidídimo de touros. Ciência Rural, 44(9): 1658-1663, 2014.

Bonaura, M.C.; Jurado, S.; Favre, R.N.; Praderio, R.; Tittarelli, C.; Stornelli, M.A. Alteraciones Ultramicroscópicas Observadas en Espermatozoides Felinos (Felis catus) Congelados-Descongelados Revista Ciencias Morfológicas, 15(2): 25-33, 2013.

Brusentsev, E.; Kizilova,E.; Mokrousova,V., Kozhevnikova,V.; Rozhkova, I.; Amstislavsky,S. Characteristics and fertility of domestic cat epididymal spermatozoa cryopreserved with two different freezing media. Theriogenology, 110: 148-152, 2018.

Buranaamnuay, K. Sperm-TALP: An Alternative Extender for Retrieving and Diluting Epididymal Sperm in the Domestic Cat. Reproduction in Domestic Animals, 48(6): 912-917, 2013. 
Buranaamnuay, K. Determination of appropriate cryopreservation protocols for epididymal cat spermatozoa. Reproduction in Domestic Animals, 50(3): 378-385, 2015.

Buranaamnuay, K. Protocols for sperm cryopreservation in the domestic cat: a review. Animal Reproduction Science, 183: 56-65, 2017.

Buranaamnuay, K. Cryopreservation and storage of cat epididymal sperm using- $75^{\circ} \mathrm{C}$ freezer vs liquid nitrogen. Animal Reproduction Science, 2018.

Chatdarong, K.; Axner, E.; Manee-In, S.; Thuwanut, P.; Linde-Forsberg, C.; Pregnancy in the domestic cat after vaginal or transcervical insemination with fresh and frozen semen. Theriogenology, 68: 13261333, 2007.

Chatdarong, K.; Thuwanut, P.; Morrell, J.M. Single-layer centrifugation through colloid selects improved quality of epididymal cat sperm. Theriogenology, 73(9): 1284-1292, 2010.

Chatdarong, K.; Thuwanut, P.; Manee-In, S.; Lohachit, C.; Axnér, E. Effects of Thawing Temperature and Post-thaw Dilution on the Quality of Cat Spermatozoa. Reproduction in Domestic Animals, 45(2): 221-227, 2010.

Chatdarong, K. Retained fertilizing capability in cryopreserved feline spermatozoa.

Reproduction in Domestic Animals, 52(2): 261-264, 2017.

Cheuquemán, C.; Faúndez, R.; Sánchez, R.; Risopatrón, J. Changes in sperm function and structure after freezing in domestic cat spermatozoa. Andrologia, 50(9): 1-8, 2018.

Cocchia, N.; Ciani, F.; El-Rass, R.; Russo, M.; Borzacchiello, G.; Esposito, V.; Montagnaro, S.; Avallone, L.; Tortora, G.; Lorizio, R.Cryopreservation of feline epididymal spermatozoa from dead and alive animals and its use in assisted reproduction. Zygote, 18(1): 1-8, 2010.

Deco-Souza, T.; Paula, T.A.; Costa, D.S.; Costa, E.P.; Barros, J.B.G.; Araújo, G.R.; Carreta-Jr, M. Comparação entre duas concentrações de glicerol para a criopreservação de sêmen de suçuarana (Puma concolor). Pesquisa Veterinária Brasileira, 33(4): 512-516, 2013.

Emerenciano, K.D.M.; Lima, G.L; Peixoto, G.C.X; Silva, M.A.; Oliveira, M.G.C.; Paula, V.V; Silva, A.R. Recuperação de espermatozoides epididimários de gatos domésticos (Felis catus) utilizando soluções à base de tris ou água de coco em pó. Acta Veterinaria Brasilica, 7(2): 148-153, 2013.

Gañán, N.; Gomendio, M.; Roldan, E.R.S. Effect of storage of domestic cat (Felis catus) epididymides at $5^{\circ} \mathrm{C}$ on sperm quality and cryopreservation.Theriogenology, $\quad 72(9)$ : 1268-1277, 2009.

Hay, M.; Goodrowe, K.L. Characteristics and zona binding ability of fresh and cooled domestic cat epididimal spermatozoa. Theriogenology, 40: 967-975, 1993.

Hashemitabar, M.; Sabbagh, S.; Orazizadeh, M.; Ghadiri, A.; Bahmanzadeh, M. A proteomic analysis on human sperm tail: comparison between normozoospermia and asthenozoospermia.Journal of assisted reproduction and genetics, 32(6): 853-863, 2015.

Hermansson, U.; Axnér, E. Epididymal and ejaculated cat spermatozoa are resistant to cold shock but egg yolk promotes sperm longevity during cold storage at $4^{\circ} \mathrm{C}$.Theriogenology, 67(7): $\quad 1239-1248$, 2007.

Jiménez, E.; Perez-Marın, C.C.; Vizuete, G.; Millan, Y.; Aguera, E.I. Effect of different extenders on in vitro characteristics of feline epididymal sperm during cryopreservation. Reproduction in Domestic Animals, 48(4): 665-672, 2013

Klaus, C.; Eder, S.; Franz, C.; Muller, K. Successful Cryopreservation of Domestic Cat (Felis catus) Epididymal Sperm after Slow Equilibration to 15 or $10^{\circ} \mathrm{C}$. Reproduction in Domestic Animals, 51(2): 195-203, 2016.

Kunkitti, P.; Bergqvista, A.S.; Sjunnessona, Y.; Axnér, E. The ability of feline spermatozoa in different epididymal regions to undergo capacitation and acrosome reaction. Animal Reproduction Science, 161: 64-74, 2015.

Kunkitti, P.; Axnér, E.; Bergqvist, A.S.; Sjunnesson, Y. In vitro fertilization using frozen-thawed feline epididymal spermatozoa from corpus and cauda regions. Theriogenology, 86: 1403-1408, 2016.

Kunkitti, P.; Chatdarong, K.; Suwimonteerabutr, J.; Nedumpun, T.; Johannisson, A.; Bergqvist, A.S.; Sjunnesson, Y.; Axnér, E. Osmotic tolerance of feline epididymal spermatozoa. Animal Reproduction Science, 185: 148153, 2017. 
Lambo, C.A.; Grahn, R.A.; Lyons, L.A.; Bateman, H.L.; Newsom, J.; Swanson, W.F. Comparative fertility of freshly collected vs frozen-thawed semen with laparoscopic oviductal artificial insemination in domestic cats. Reproduction Domestical Animal 47 6): 284-288, 2012.

Lima, D.B.C; Silva, H.R.; Carvalho, G.G.; Pinto, J.N.; Pinheiro, B.Q.; Silva, L.D.M. Recuperação de espermatozoides epididimários de gato doméstico através da técnica de flutuação. Acta Veterinaria Brasilica, 8:198-199, 2014.

Lima, D.B.C.; Silva, T.F.P.; Cortez, A.A.; Pinto, J.N.; Magalhães, F.F.; Caldini, B.N.; Silva, L.D.M. Recovery of sperm after epididymal refrigeration from domestic cats using ACP$117 \mathrm{c}$ and Tris extenders. Arquivo Brasileiro de Medicina Veterinária e Zootecnia, 68(4): 873-881, 2016.

Macente, B.I; Mansano, C.F.M.; Pereira, M.M.; Martins, M.I.M.; Gioso, M.M.; Savi, P.A.P.; Gutierrez, R.R. Congelação de espermatozoides epididimários de gatos utilizando o diluidor Botu-crio ${ }^{\circledR}$ após refrigeração por $24 \mathrm{~h}$ em contêiner de transporte de sêmen Botutainer (®. Acta Veterinaria Brasilica, 6(2): 112-117, 2012.

Manee-In, S.; Parmornsupornvichit, S.; Kraiprayoon, S.; Tharasanit, T.; Chanapiwat, P.; Kaeoket, K. L-carnitine supplemented extender improves cryopreserved-thawed cat epididymal sperm motility. AsianAustralasian journal of animal sciences, 27(6): 791, 2014.

Martins, M.I.M.; Justino, R.C. Criopreservação espermática em felinos: estado da arte. Revista Brasileira de Reprodução Animal, 39(1): 129-135, 2015.

Mota, P.C.; Ramalho-Santos, J. Comparison between different markers for sperm quality in the cat: Diff-Quik as a simple optical technique to assess changes in the DNA of feline epididymal sperm. Theriogenology, 65 (7): 1360-1375, 2006.

Mota-Filho, A.C.; Silva, L.D.M. Recuperação e conservação de espermatozoides epididimários de mamíferos. Acta Veterinaria Brasilica, 6 (1): 1-8, 2012.

Oliveira, K.M.; Muzzi, L.A.L.; Torres, B.B.J.; Alves, E.G.L.; Sampaio, G.R.; Muzzi, R.A.L. Estudo comparativo entre três técnicas abertas de orquiectomia em gatos. Acta Scientiae Veterinariae. 38(2): 177-183, 2010.

Patrick, J.; Comizzoli, P.; Elliott, G. Dry preservation of spermatozoa: considerations for different species. Biopreservation and biobanking, 5(2): 158-168, 2017.

Platz, C.C.; Wildt, D.E.; Seager, S.W.J. Pregnancy in the domestic cat after artificial insemination with previously frozen spermatozoa. Journal of Reproduction and Fertility, 52(2): 279282, 1978.

Prochowska, S.; Niżański, W.; Partyka, A.; Kochan, J.; Młodawska, W.; Nowak, A., Skotnicki, J.; Grega, T.; Pałys, M. Influence of the type of semen and morphology of individual sperm cells on the results of ICSI in domestic cats. Theriogenology. 2018. doi: 10.1016/j.theriogenology.2018.10.031.

Pukazhenthi, B.; Pelican, K.; Wildt, D.; Howard, J. Sensitivity of domestic cat (Felis catus) sperm from normospermic versus teratospermic donors to cold-induced acrosomal damage. Biology of Reproduction, 61(1): 135-141, 1999.

Pukazhenthi, B.S.; Wildt, D.E.; Howard, J.G. The phenomenon and significance ofteratospermia in felids. Journal of reproduction and fertility. Supp lement, 57: 423-33, 2001.

Pukazhenthi, B.S.; Neubauer, K.; Jewgenow, K.; Howard, J.; Wildt, D.E. The impact and potential etiology of teratospermia in the domestic cat and its wild relatives. Theriogenology, 66(1): 112-121, 2006.

Savi, P.A.P.; Motheo, T.F.; Padilha-Nakagi, L.C.; Pires-Buttler, E.A.; Vicente, W.R.R. Técnica modificada de compressão do ducto deferente e cauda do epidídimo para obtenção de espermatozoides caninos. Investigação, 14(1): 18-22, 2015.

Silva, S.V.; Guerra, M.M.P. Efeitos da criopreservação sobre as células espermáticas e alternativas para redução das crioinjúrias.

Revista Brasileira de Reprodução Animal, 35(4): 370-384, 2011.

Souza, W.L.; Morais, E.A. Atividade antioxidante da melatonina sobre o estresse oxidativo em espermatozoides: revisão de literatura. Revista Eletrônica Nutritime, 13: 48314839, 2016.

Spindler, R.E.; Wildt, D.E. Circannual variations in intraovarian oocyte but not epididymal 
sperm quality in the domestic cat. Biology of Reproduction. 61: 188-194, 1999.

Stachecki, J.J.; Ginsburg, K.A.; Amant, D.R. Stimulation of cryopreserved epididymal spermatozoa of the domestic cat using the motility stimulants caffeine, pentoxifylline, and 2'-deoxyadenosine. Journal of Andrology. 15: 157-164, 1994.

Terrell, K.A.; Wildt, D.E.; Anthony, N.M.; Bavister, B.D.; Leibo, S.P.; Penfold, L.M.; Marker, L.L.; Crosier, A.E.Evidence for compromised metabolic function and limited glucose uptake in spermatozoa from the teratospermic domestic cat (Felis catus) and cheetah (Acinonyx jubatus). Biology of Reproduction, 83(5): 833-841, 2010.

Tittarelli, C.M.; Jurado, S.B.; Nuñez-Favre, R.; Bonaura, M.C.; Sota, R.L.; Stornelli, M.A. Effect of storage media and storage time on histological and ultrastructural changes in cat epididymal cells. Reproduction in Domestic Animals, 47(6): 281-283, 2012.

Thuwanut, P.; Chatdarong, K.; Techakumphu, M.; Axner, E. The effect of antioxidants on motility, viability, acrosome integrity and DNA integrity of frozen-thawed epididymal cat spermatozoa. Theriogenology, 70(2): 233-240, 2008.

Thuwanut, P.; Chatdarong, K.; Johannisson, A.; Bergqvist, A.S.; Söderquist, L.; Axnér, E. Cryopreservation of epididymal cat spermatozoa: effects of in vitro antioxidative enzymes supplementation and lipid peroxidation induction. Theriogenology, 73(8): 1076-1087, 2010.

Thuwanut, P.; Arya, N.; Comizzoli, P.; Chatdarong, K. Effect of extracellular adenosine 5 -triphosphate on cryopreserved epididymal cat sperm intracellular ATP concentration, sperm quality, and in vitro fertilizing ability. Theriogenology, 84(5): 702-709, 2015.
Thuwanut, P.; Tipkantha, W.; Siriaroonrat, B.; Comizzoli, P.; Chatdarong, K. Beneficial effect of extracellular adenosine 5'triphosphate treatment on the Indochinese leopard (Panthera pardus delacouri) sperm quality after cryopreservation. Reproduction in Domestic Animals, 52 (S2): 269-274, 2017.

Toniolli, R.; Toniollo, G.H.; Franceschini, P.H.; Morato, F.M.A. Uso do diluente BTS no processo de congelação do sêmen suíno: II. Modificações na técnica. Ciência animal, 25(4): 44-59, 2015.

Toniolli, R.; Guimarães, D.B.; Barros, T.B. Proteínas do sêmen e sua relação com a resistência à congelação em ejaculados de diferentes varrões. Revista Brasileira de Reprodução Animal, 41(1): 297-311, 2017.

Vick, M.M.; Bateman, H.L.; Lambo, C.A.; Swanson, W.F. Improved cryopreservation of domestic cat sperm in a chemically defined medium. Theriogenology, 78: 2120-2128, 2012.

Villaverde, A.I.S.B.; Fioratti, E.G; Penitenti, M.; Ikoma, M.R.; Tsunemi, M.H.; Papa, F.O.; Lopes, M.D. Cryoprotective effect of different glycerol concentrations on domestic cat spermatozoa. Theriogenology, 80(7): 730737, 2013.

Vizuete, G.; Jiménez, E.; Agüera, E.I.; PérezMarín, C.C. Impact of Ultra-Rapid Freezing on the Motility, Morphology, Viability and Acrosome Integrity of Epididymal Cat Sperm Diluted in Sucrose-Based Extenders. Reproduction in Domestic Animals, 49(1), 2014.

Waurich, R.; Ringleb, J.; Braun, B.C.; Jewgenow, $\mathrm{K}$. Embryonic gene activation in in vitro produced embryos of the domestic cat (Felis catus). Reproduction, 140 (4): 531-540, 2010. 